\title{
Chinese Higher Education Enrollment Policy: Fairness of System for Students' Choice of University
}

\author{
Muhammad Azeem Ashraf \\ Faculty of education, Beijing Normal University, Beijing, China \\ azeem20037@gmail.com
}

\begin{abstract}
China has made a great progress in the expansion of higher education system in recent years. The enrollments into higher education institutes has been increased from 3\% in 1991 to $27 \%$ in 2010 and it is projected that gross enrolment rate in higher education will increase to $40 \%$ by 2020 . China has made a lot of policies and reforms during this massive expansion of its higher education system. This paper deals with the enrollment policy for students in which students has to make choice for university before or after taking College Entrance Exam. The focus of this paper is, how much fair is this system for the Chinese students to make choice for university, challenges for students in making choice for university, different governmental policies in different provinces which creates imbalance between students and universities and what government should do to bring fairness in enrollment system.
\end{abstract}

Index Terms - Chinese College Enrollment, Choice of University, Policy

\section{Introduction}

China is eagerly spearheading a massive expansion of higher education in a very radical way in recent years, enrolment has been doubled in just 3 years and the participation rate has reached 17\% (Chen, 2004). This double enrolments has reached 16-odd million in 2003, with a massive increased from $3 \%$ in 1991 to $27 \%$ in 2010 . It is projected that gross enrolment rate in higher education will increase to $40 \%$ by $2020^{1}$ (MOE, 2010). Higher Education Institutions (HEIs) have shown positive response in the enrollment ration of student. According to a survey made by the Beijing Municipal Education Commission in 2002, all 50 colleges and universities surveyed are adopting a cautious attitude towards enrolment (Hua, 2002). Among those surveyed, $63.8 \%$ hold a positive attitude to enrolment expansion.

College admissions in China are centralized processes via standardized tests. This centralized process was established in 1952 by the National Ministry of Education after years of decentralized examinations and admissions. Prior to 1950, each college organized its own entrance examination and admission system to admit students. Like other decentralized processes, these college admissions systems suffered from a coordination problem: Some famous HEIs could not recruit enough students even after many times of examinations and enrollments. As many good students took many times of examination and received admission offers from several HEIs, they would forgo

\footnotetext{
${ }^{1}$ Data source: Ministry of Education, China (MOE) website. retrieved on 2014-01-04 from

http://www.moe.gov.cn/publicfiles/business/htmlfiles/moe/s4668/201008/9 3785.html
}

the admission offers from some HEIs; as a result, the final rate of enrollment in some HEIs was very low. In some HEIs the rate of enrollment was lower than $20 \%$ (Yang, 2010). To fix this problem, 73 colleges formed three regional alliances in 1950; each alliance implemented a centralized process for admissions. Subsequently, the Ministry of Education decided to organize the first National College Entrance Examination (NCCE), to assign students via national centralized processes

Each province has a Student Placement Office which is responsible to assign high school graduates to colleges slots (Zhu, 2013). This office organizes a NCCE for students who planning to attend colleges and ranks students according to their test scores. Students are also asked to report a list indicating preferences among colleges. Given the ranking of students via test scores and students' reported preferences, the Student Placement Office assigns students to college slots under a specific system.

The college admission process in China begins with a college application. As of 2010, in Beijing, Shanghai, and Tianjin, students must file a college application before taking the NCEE; in Shanxi, Liaoning, Jiangxi, Tibet, and Xinjiang, students file an application after they take the exam but before they know their scores; in the remaining provinces ${ }^{2}$ students file an application after receiving the NCEE score reports ${ }^{3}$.

This research paper mainly focuses on students' choice of universities in different provinces of china. As different provinces have different policies for students to choose their desired universities for higher education and this different policy system creates unfairness and imbalance among students from different provinces.

College admissions in China proceed sequentially in tiers. Colleges are categorized into different tiers in decreasing prestige: Key colleges (i.e., National 985 and 211 universities) belong to the first tier and admit students first; ordinal colleges belong to the second tier; and vocational training colleges are included in the third tier. Only when assignments in the first tier are finalized, admissions in the second tier start, and so on.

During the whole process, a certain system of enrollment is used across tiers which are predetermined by each province (Ma, 2013). In each tier, the system of enrolment and choice of

\footnotetext{
${ }^{2}$ Including Hebei, Inner Mongolia, Jilin, Heilongjiang, Jiangsu, Zhejiang, Anhui, Fujian, Shandong, Henan, Hubei, Hunan, Guangdong, Guangxi, Hainan, Chongqing, Sichuan, Guizhou, Yunnan, Shaanxi, Gansu, Qinghai, and Ningxia

${ }^{3}$ Data source: gaokao.eol.cn,

http://gaokao.eol.cn/kuai_xun_3075/20100610/t20100610_484751.shtml.
} 
universities works as follows: in the first round, all students compete for their first choice colleges; in the second round, students rejected in the first round compete for their second choice colleges, if those colleges have available slots, and so forth, until all chosen colleges are considered for unassigned students or there is no available college slot in the current tier. For a given college, slots are allocated among students who rank it the same in their preference lists, but students who rank it highly in the preference list have strict priority over those who do not.

This system of enrollment has been criticized by the public for years for some serious deficiencies. The main criticism is the unfair enrollments for students from different provinces. For instance, it is possible for students with higher test scores to receive worse assignments than those with lower test scores (Ruoling, 2010). This creates questions for the fairness of enrollment system. Each year, many stories can be found in the news after finishing university enrollments, like the following story published on online news website, parents shared their son's story of taking NCEE but couldn't enroll in university even his marks was more than the required marks for first tier universities.

"My son took this year's college admissions. His test score was 658 , which is higher than the merit score for the previous years of his first choice college. However, this year's merit score for his first choice college was 660 , so he was rejected by his first choice college. As other choice colleges are filled and not accepted him, in the end, my son failed to be admitted by any good college although his test score is high enough for admission. He was so disappointed that he decided to quit it ${ }^{4}$."

\section{Research Framework}

The research framework for this paper has taken from Guang Yu Tan's article ${ }^{5}$ which is built upon Martin Trow's theory. Trow (2007) suggests the transformation of higher education goes through three phases 1) elite--shaping the mind and character of ruling class in preparation for elite roles; 2) mass--transmission of skills and preparation for a broader range of technical and economic elite roles; and 3) universal-adaptation of the "whole population" to rapid social and technological change $(\mathrm{p}, 243)$. This transition from elite to mass needs changes in all their structure and functions. This is beyond the scope of this research paper to cover all the aspects of this transition so this paper will only focus on the enrollment policy for Chinese HEIs in terms of choice of universities before NCEE, after NCEE but before knowing the score and after knowing the score of their NCEE.

Different researchers have found inequalities in enrollment policy for Chinese higher education. According to Bai, C., et al (2013) in each year, under the guidance of the Ministry of Education, each college and university sets the target

\footnotetext{
4 See http://learning.sohu.com/20070918/n252207517.shtml, posted on 2007/09/18 and retrieved on 2014/1/5

${ }^{5}$ Tan, G. Y. (2013). HIGHER EDUCATION REFORMS IN CHINA: FOR BETTER OR FOR WORSE?. International Education, 43(1)
}

number of examinees to be admitted from each province. Universities and colleges begin their admission in the following order: first, special colleges; second, the first-tier universities; third, the second-tier universities; and finally, junior colleges. Each university and college selects applicants based on applicants' NCEE score from the highest to the lowest until the admission quota is reached. By the end of the admission process, each student gets one offer. A student can choose not to go to the offered school. In such case, the student will need to retake the NCEE next year and go through the application and admission procedure again.

Chinese provinces have different population and different educational developments including the number and type of universities. Chinese Higher Education Institutions accept about $99 \%$ of their students based on the NCEE. As a result students spend a great amount of time preparing for the exam. Nevertheless, not all of students score the desirable mark to join universities. And they have to choose different number of universities where they want to continue their higher education after taking NCEE. As different provinces adopted different system for choosing university, therefore there are different disparities among the provinces.

\section{Research Methodology}

This section is focused on sample size and sampling strategy, methods of data collection, significance, scope and limitations of the study and data analysis.

\subsection{Sample Size and Sampling Strategy}

Undergraduate students of first tier university located in Beijing, who are enrolled through three different systems (i.e. choosing university before taking NCEE, after NCEE but before result and after announcing the result) will be used as a sample for collecting data. The case school is selected for sampling because of researcher live in this school and it's easy and convenient for researcher to find time for sampling. And another reason is that this university is first tier university which enrolls more than two thousand new students every year from all provinces of China. Moreover, undergraduate students are selected deliberately because they have been enrolled in this university recently.

The total sample size of respondents is 9 students and these students will be selected from sample university using convenience sampling. These 9 students come from different province in China. A quota sampling has been used which is of 3 students from those provinces where they choose university before taking NCEE, 3 students from those provinces where they choose university after taking NCEE but before announcing result and rest of 3 students from those provinces where they choose universities after taking NCEE and announcing the result.

\subsection{Methods of Data Collection}

All the collected data is qualitative and used to investigate fairness of choosing universities in enrollment system for higher education. Method of data collection is face to face, semi structured interview. This is because semi-structured in- 
terview is helpful in getting enough information by making questions flexible and allowing the researcher to ask additional questions based on what an interviewee responds (Alan, 2008).

The purpose of the study has been explained to the interviewee students and their participation for sampling to this study is voluntary.

\subsection{Significance, Scope and Limitations of the Study}

Investigating the fairness of choosing universities in enrollment system will help all other prospective examinees to learn from experience of the previous students. The study may also be applied to enrollment policies in other education institutes like high school or primary school. Moreover, the research can be used as a base for further studies on the factors that determine students 'challenges in current enrollment policy.

However, due to financial and time limitations, the study has confined only in one university. Besides, lack of adequate data especially from parents, high school teachers and other stakeholders that would help in expanding the study has made the study to depend on students' responses. Therefore, this research is far from claiming that the study has completed enough to be generalized.

\subsection{Data Analysis}

Qualitative data analysis has been used to present and analyze the collected data. The finding of the interviews is analyzed by using descriptive and explanatory methods, with a continuous reference to the literature and previous empirical studies. Some finding are also be analyzed thematically.

\section{Research Findings}

According to the literature review and interview findings, research findings have been divided into three different categories, and these categories are according to the system of choosing university by students. These all findings are very important and as Gu (2011) cited in "Spatial recruiting competition in Chinese higher education system" from Marginson (2006)

"Every year, colleges and universities set their different admission score levels to different provinces according to different factors such as regional student quality, regional education development level, and local enrollment competition. The process of setting regional admission score level for every university is complex and dynamic because there are strategic interactions between competitive universities in each target region. Such strategic interactions between competitive universities mean dynamic competition in higher education enrollment field (Marginson 2006).

The interviewees are from different provinces, so research findings are referenced with their provinces to avoid the conflict with policies from other provinces in china.

\subsection{Choosing University before Taking NCEE}

Students who take NCEE in Beijing has to fill the application form for applying university before taking the NCEE, and they have to choose three universities according to their choice in three ranks of choices (i.e. first choice university, second and third choice university). They will be enrolled by their first choice university if their score match with first choice university, but if it doesn't match, they have to wait for their second choice university's decision, if they couldn't get enroll into second choice then wait for their third choice university's decision. At the end, if they couldn't get offer from all their three choice universities, they have to take NCEE again next year. As one of the interviewee showed her fear of choosing university,

"Filling the form for choosing university before exam is not good, because I always had fear of wasting my one year if I couldn't enroll into my first choice university. We can make better choice of university and our future career if we know our score before choosing the university".

When students make their choice of universities, they have to consider the choice of major also with regard of universities, as different universities are specialized in different majors and different merit list applied for different majors inside every university. So students have to compete with two merit lists, one is for university selection and another is for major selection. One interviewee reflected herself like this,

"it was my dream to study in Peking University, and I really worked very hard, but I was afraid of competition as every student wants to study in this university, so I chose another university as my first choice, but when I got my NCEE score, I was very sad and disappointed because my score was much higher than the merit list of Peking university, but I couldn't enroll myself there and students with lower score than me were enrolled there"

Students consult with their parents in making the choice of universities, and mostly they choose the university which their parents Believe it's better for their career development in the future or which university is closer to their home. But they also consult with their teachers and friends about choice of university. As one interviewee had to change his choice of university because of her mother,

"I wanted to study in Zhejiang University because I like it and it is one of best universities in china, but my mother didn't allow me because she thinks it's too far from our hometown so I chose university in Beijing which is near to my home."

\subsection{Choosing University after Taking NCEE but Before Know- ing Their NCEE Score}

Students who take NCEE in Shanxi has to fill the application form for applying university after taking the NCEE but before announcing the result. They can choose three choices of universities with same criteria as students in Beijing but different number of universities in each choice and it's different in different province. If there score cannot match with their first choice university, they have to wait for second choice university, if couldn't enroll in second choice university then wait for third choice. They have to wait for next year and take another NCEE next year if they couldn't enroll by any university of their choice on application form. One interviewee reflected his thoughts about this experience as,

"After taking NCEE, my next step was making a choice of university, and it was really difficult for me as there are 
many universities and every university has different merit list. I had to make sure that I can get high score for merit list of my choice of university and finally I got admission in my first choice university. It was great relief for me and my family".

When students fill the form after taking NCEE, they also have to consider the second merit list for majors, because different universities have different merits for different majors.

These students also consult it with their parents, teachers and friends before making choice of universities, but parents play more effective role and they choose university for their children as they think they know better what is good for their children.

\subsection{Choosing University after Taking NCEE and Knowing NCEE score}

Students who take NCEE in Hebei, province are allowed to fill the application form for applying university after taking the NCEE and announcing the result. they can match their score in NCEE with different universities according to universities' merit list for Hebei province, and fill the application form with same criteria like Beijing and Shandong which is choose three choice of universities and wait for universities' decision for student's enrollment. As one student told his experience,

"I always wanted to go to top ranked universities like Peking University or Tsinghua University, and my first year NCEE score was below the score levels of those top universities so I decided to take another NCEE next year, my score was again lower than these universities' merit list but it was good enough to enroll in another top ranked university.it was my choice of wasting my one year's time and I'm happy with that".

When students fill the form after knowing their NCEE score, they have to check university's merit list and also merit list for different majors in the same university. But they knew their score before choosing university which makes their choice easy. But it creates a difference among students' with different NCCE score and from different schools. One interviewee said,

"As everyone knows their score and everyone want to go to best universities, so students with higher score in NCEE can only go to top ranked universities"

Another interviewee shared an example of their province,

"This year (2013) from my province (Hebei), one hundred and four students were enrolled in Peking University and Tsinghua University graduated from only one school. So there was no chance for students from other schools to enroll into these universities."

These students also consult their choice of university with their parents, teachers and friends, but again parents play more dominant role and they prefer to choose university for their children.

\section{Discussion}

Analysis of strategic interaction between universities has recently become a major focus of administering authority of government and social scientists $(\mathrm{Gu} 2011$ cited from
McMillen et al. 2007; Millimet and Rangaprasad 2007a; Ghosh 2010). Such interaction in enrollment competition field of higher education includes students' choice of universities for their higher education.

This study investigates the effects of different systems of choosing university on students' career and how much fairness is in this system for students. Students' experience of choosing universities for higher education has great of value. They have to go through different systems from different provinces to enroll even in one university. for example, for applying Beijing normal university, student's from Beijing choose it their first choice before taking NCEE, students from Shanxi choose it as their first choice after taking NCEE but without knowing their NCEE score and students from Hebei province choose it as their first choice after taking NCEE and knowing their NCEE score.

These three different systems inside one centralized system create an imbalance of opportunities and disparities among students from different provinces. Gu (2011) stated in his research on higher education in china that the enrollment competitive behavior of higher education institutes in China can be influenced by the size of neighborhood competitors. This competition can be seen among students trying themselves to be enrolled in china's best universities.

First, the students who choose university before taking exam are on high risk (Zhu, 2013). they choose their university on their abilities to get score in the NCEE, as every student dreams to go to top universities of china, so they want to choose top university but they are afraid of choosing because if they can't get the merit list score for their choice of university, they have to take NCEE again next year and waste of their one year.

Once these students choose their university, they start preparing NCEE to get enrolled into their first choice of university. It becomes their goal to get higher score than the merit list of that university.

Empirical evidence further illustrates the severity of the problem: For example, in 2005, over 800 students failed to be admitted by first-tier colleges in Gansu province (Nie, 2007).

But there is another fact, there are many students who get very high score in CEE which is good enough to enter into top ranked universities like Peking University or Tsinghua University, but they can't get enrolled into those top universities only because they didn't choose these universities as their first choice. This fact creates a question on the rationality of CEE (Ruoling, 2010) that who should be admitted by top ranked universities, the students who got high marks in CEE or the ones who choose top ranked universities at their first choice with low CEE score? And all these phenomena create the issue on the fairness (Meyer, 2013) of higher education system where students with low scores are admitted in universities and with lower scores left out.

By this choice, students also take a risk in listing their first choices. If students are rejected by their first choice college, they are very likely to be rejected by the next choice colleges as these colleges are filled with students who list them 
higher in their preference lists. This gives students a strong incentive to manipulate their true preferences, carefully choosing safe colleges as the first choice and thus ensuring a higher chance of being admitted. Consequently, students are forced to play a complicated admission game induced by the choice of universities, and usually it is beneficial for them to manipulate their true preferences. This point has also been advocated by some researchers working on college admissions reform ${ }^{6}$

The system of choice of universities emphasizes the choices students make. Whether they are accepted by colleges does not only depend on students' own test scores, but also on how other students make choices

Second, the student who make their choice of university after taking NCEE are also at risk but less than those who choose before taking NCEE. As Zhu (2013) argue that students are always at risk when they make choice of university. These students have an idea how much score they can get in NCEE and they make their choice based on their NCEE experience. But they are always at risk because they don't know how much exact score they can get and how many students applied for the same university.

The Ministry of Education also provides some advice on how to strategize in the sequential choice algorithm on its official website for college admissions ${ }^{7}$

"Students should carefully make their first choice, choosing colleges for which their test scores are above the average of the past year's admission scores if the colleges have had stable admission scores in the past three years, and in the upper bound of the past year's admission scores if the colleges have had unstable admission scores in the past three years."

"Students should have safe colleges for their second choice. The second choice colleges should be among those that had available slots in the second round in previous years, so that students still have a chance of being admitted by their second choice colleges even if rejected by their first choice colleges."

Third, the students who make their choice of university after knowing their NCEE score. It makes things very easy for these students as they can match their score with all universities which they want to study. As one interviewee said,

"It was very easy for me to make my choice for university, because I knew my score in NCEE and I knew the average score for merit of universities so I could choose any university matched with my NCEE score".

And these students don't have any fear of wasting their one year if they couldn't get merit list score of their selected universities as they already know their score before making choice of university. And it will be students' own choice if they want to repeat NCEE to get higher score for a better university if their score was lower than their desired university's merit list. But there is another fact of this choice system: students showed in interview as top schools dominate top universities.

\footnotetext{
${ }^{6}$ See http://gaokao.chsi.com.cn/gkxx/zjsd/201003/20100311/65908711.html, retrieved on 2014-01-02

${ }^{7}$ See http://gaokao.chsi.com.cn/gkxx/zytb/201106/20110616/214533410-

2.html, retrieved on 2014-01-04.
}

The example from Hebei province told by the interviewee again illustrates the issue on fairness of this system.

Fourth, other factors which effects on students" choice for universities like parents, family, friends, teachers etc. Family characteristics that influence students' education include family income, parental education, family structure, religion, ethnicity, caste, and parental engagement (Chudgar and Shafiq, 2010). Parents play an important role in students' academic career and their choice of university as well. This shows that students' choice depends on not only their own choice but on parents' choice as well. Giordano, Phelps, Manning and Longmore (2008) explain that parents' academic attainment has a major effect on the success of students. One interviewee even didn't fill his form as his father did everything for him,

"I didn't know my first choice of university till the day when I received offer from that university as my father filled the form and he chose university for me."

\section{Conclusions}

The enrollment system in HEIs and making choice of university has gone through several phases, and a lot of reforms have already been done to bring the fair system among different admission policies. Ministry of education and other education departments at provincial and county levels have changed their policies in recent years to give more benefits to students to bring fairness in the system. But three different systems of making choice of university for students from different provinces create issue of fairness. To remove unfairness and students' incentive in this system, the education department in Hunan province became the first, in 2003, to replace the single choice of university system with a new parallel choice system. Later in 2005 and in 2007, this parallel choice was also introduced separately in Jiangsu province and Zhejiang province. Parallel choice means that students can list several "parallel" colleges in decreasing desirability for each choice. In this way, each college slot is sequentially allocated for students with the highest test score to those who with the lowest test score.

Imbalance would be created by students sitting in the same classroom but coming to the same university from different entrance admission systems. Ministry of education and provincial education departments should need to adopt a central enrollment policy which gives equal opportunities for all students from all over the country. This could help student save one year of going through and retaking the NCEE. There should be equal opportunities for all students to enroll into universities.

Chinese government should focus more on the equality of opportunities for all students in the country. The role of HEIs should be also discussed to help make the admission procedure and overcome the disparities between students and universities.

\section{References}

[1] Bai, C. E., Chi, W., \& Qian, X. (2013). Do college entrance examination scores predict undergraduate GPAs? A tale of two universities. China Economic Review. 
[2] Chen, D. Y. (2004). China's mass higher education: Problem, analysis, and solutions. Asia Pacific Education Review, 5(1), 23-33.

[3] Chudgar, A., \& Shafiq, M. N. (2010). Family, community, and educational outcomes in South Asia. Prospects, 40(4), 517-534.

[4] Francis, A. M., \& Tannuri-Pianto, M. (2012). The redistributive equity of affirmative action: Exploring the role of race, socioeconomic status, and gender in college admissions. Economics of Education Review, $31(1), 45-55$.

[5] Gu, J. (2012). Spatial recruiting competition in Chinese higher education system. Higher Education, 63(2), 165-185.

[6] Harman, G. (1994). Student selection and admission to higher education: Policies and practices in the Asian region. Higher Education, 27(3), 313-339.

[7] Jacob, W. J. (2006). Social Justice and Gender in Chinese Higher Education: Regional Issues of Equity and Access. In Education and Social Justice (pp. 139-159). Springer Netherlands.

[8] Li, M. (2012). On the Fairness of the Higher Education in China. Higher Education Studies, 2(2), p163.

[9] Liu, H., \& Wu, Q. (2006). Consequences of college entrance exams in China and the reform challenges. KEDI Journal of Educational Policy, $3(1), 7-21$.

[10] Ma, H. (2013). Science Teachers' Understanding of the College Entrance Examination in a Climate of National Curriculum Reform in Chi- na. In Valuing Assessment in Science Education: Pedagogy, Curriculum, Policy (pp. 183-205). Springer Netherlands.

[11] Meyer, H. D. (2013). Reasoning about Fairness in Access to Higher Education. In Fairness in Access to Higher Education in a Global Perspective (pp. 15-40). Sense Publishers.

[12] Neumann, M., Trautwein, U., \& Nagy, G. (2011). Do central examinations lead to greater grading comparability? A study of frame-ofreference effects on the University entrance qualification in Germany. Studies in Educational Evaluation, 37(4), 206-217.

[13] Ruoling, Z. (2010). On the Rationality of the College Entrance Examination. Chinese Education \& Society, 43(4), 11-21.

[14] Tan, G. Y. (2013). HIGHER EDUCATION REFORMS IN CHINA: FOR BETTER OR FOR WORSE? International Education, 43(1).

[15] Wang, L., Huang, X., \& Schnell, J. (2013). Using Burke's Dramatistic Pentad to Interpret Chinese "Gao-Kao" High Stakes Testing and Stressing- Paralleled Testing in the US as Cross-Cultural Context

[16] Yang, M. (2010). Educational System in China. Zhejiang University Press.

[17] Zhong, H. (2011). Returns to higher education in China: What is the role of college quality? China Economic Review, 22(2), 260-275.

[18] Zhu, M. (2013). College admissions in China: A mechanism design perspective. China Economic Review. 